\title{
Effect of bismuth sulfide on the electrical properties of polyethylene oxide based polymer electrolyte
}

\author{
Manoj Kumar \\ Department of Physics, D.A.V. College, Abohar, India \\ *Corresponding Author: mkverma782006@gmail.com
}

Available online at: www.isroset.org

Received: 25/May/2018, Revised: 03/Jun/2018, Accepted: 15/Jun/2018, Online: 30/Jun/2018

\begin{abstract}
Polymer electrolytes based on the polyethylene oxide and ammonium perchlorate (PEO: $\left.\mathrm{NH}_{4} \mathrm{ClO}_{4}\right)$ dispersed with bismuth sulfide are successfully prepared by in situ method. The electrical characterization of different samples is done by complex impedance spectroscopy, conductivity dispersion curve and Wagner polarization technique. Complex impedance plots are the semicircles and the intercept on the real axis showed the value of the bulk conductivities $\left(10^{-6}-10^{-5} \mathrm{~S} / \mathrm{cm}^{-1}\right)$ of the different polymeric samples. The overall conductivity of polymer electrolyte is enhanced with the dispersal of bismuth sulfide, peaks at 6 wt. \% then decreases which could be explained by Bunde et al model. Detailed I-V studies show n-type behavior of dispersoid in the composite.
\end{abstract}

Keywords: Polymer electrolyte composites, complex impedance spectroscopy, bulk electrical conductivity

\section{INTRODUCTION}

Polymer electrolyte composites have attracted a lot of attention from last three decades because of the immense potential application in solid state batteries fuel cells, supercapacitors, dye sensitized solar cells, sensors and electro chromic display devices [1-6]. The electrical conductivity of these polymer electrolyte is comparable to the liquid electrolyte with the advantage of ease of preparation, good electrode electrolyte contact and large mechanical stability. The polymer electrolyte consist of salt in association with the polymer such as polyethylene oxide, polypropylene oxide PEO, polypropylene oxide (PPO), polyacrylic acid (PAA), polyethylene imine (PEI), polyethylene glycol (PEG) etc. [7-9]. However the electrical conductivity of above mentioned polymer electrolytes at the room temperature is of the order of $10^{-4}-10^{-5} \mathrm{~S} \mathrm{~cm}^{-1}$. This poor conductivity is not desirable for device applications. Many approaches has been adopted to enhance the electrical conductivity of these polymer electrolytes [10-14]. One of the most versatile technique to enhance the electrical conductivity is preparation of the polymer electrolyte composites. In the research paper, an attempt has been made to prepare the high conducting polymer electrolyte composites in which third phase semiconductor bismuth sulfide is dispersed in pristine polymer electrolyte (PEO: $\mathrm{NH}_{4} \mathrm{ClO}_{4}$ ). The electrical characterization are investigated, compared with the existing theories and result are reported in the research paper. The present polymer electrolyte composite is beneficial as electrolyte and electrode material in the electrochemical devices.
The paper has been organized in the four distinct sections. Introduction, materials and method, result and discussion and conclusions. The section I, introduction include the brief literature review and motive behind the present work. The section II include the material and methodology adopted to prepare the present polymer electrolyte composite. The section III provide the results of the electrical investigation and detailed discussion in the form of scientific explanation and comparison with existing theories. In the last section research work is concluded and some questions are left for further study.

\section{Materials AND MethodS}

The polymer composites film are prepared by well-known in situ method [15-18]. The host polymer Polyethylene oxide (PEO) and the salt $\mathrm{NH}_{4} \mathrm{ClO}_{4}$ are added in the weight ratio of 96:4 in methanol and continuously stirred for the 3-4 hours. In the above prepared solution the salt bismuth nitrate is added in the continuous stirring of solution. The $\mathrm{H}_{2} \mathrm{~S}$ gas is slowly bubbled through the viscous solution and resulted the formation of bismuth sulfide particles in the polymer matrix. The above prepared viscous solution is poured in the petridishes for casting of the films. The films are then dried to the ambient for ten days. The dispersed bismuth sulfide particles in the composites are formed according to following reaction

$$
2 \mathrm{Bi}\left(\mathrm{NO}_{3}\right)_{3}+3 \mathrm{H}_{2} \mathrm{~S}=\mathrm{Bi}_{2} \mathrm{~S}_{3}+6 \mathrm{HNO}_{3}
$$

For the electrical characterization of the films, the small piece of the films is cut and aluminum electrodes are vacuum evaporated for the electrical contacts. 

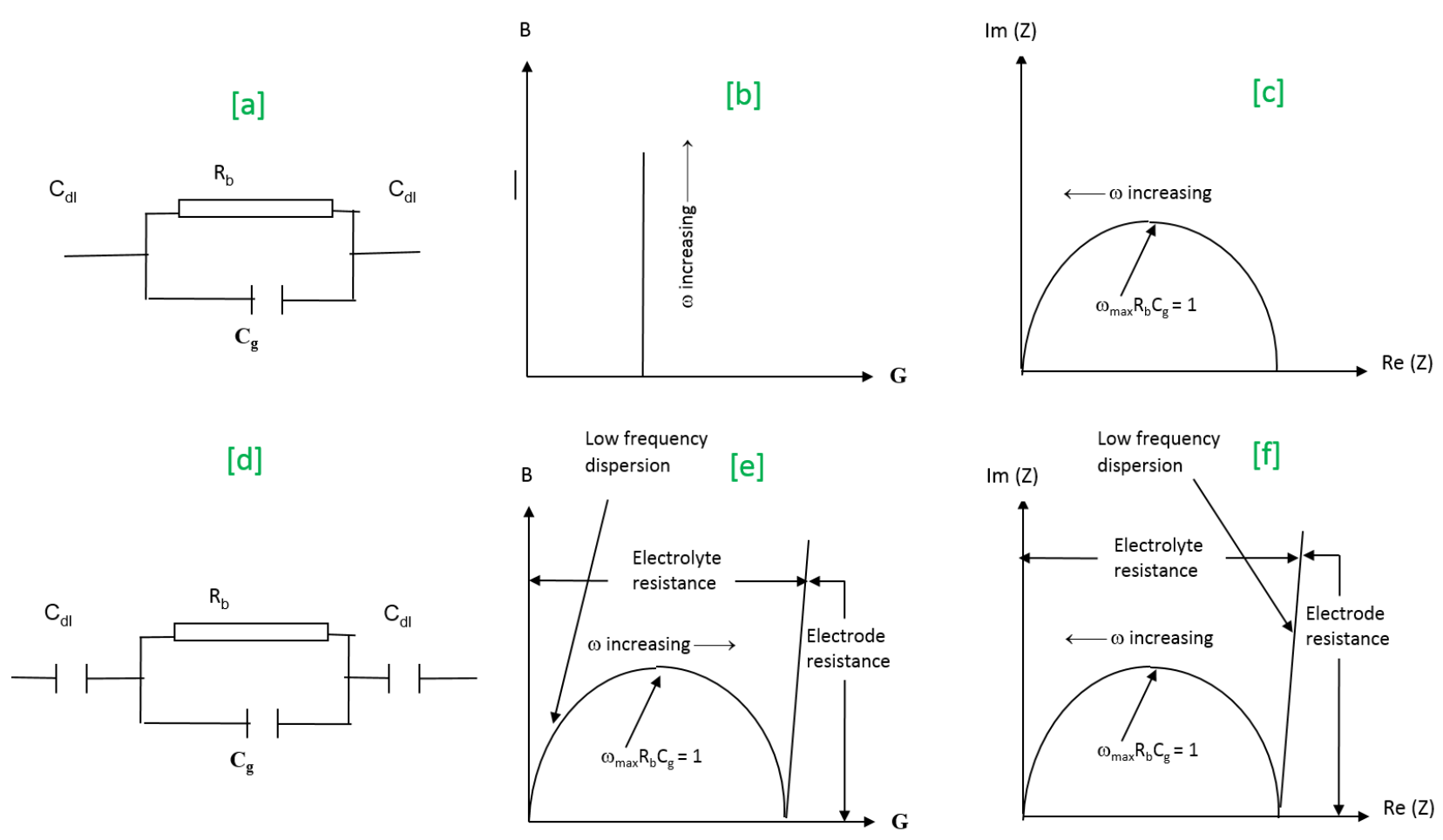

Figure 1: (a) The equivalent circuit of sample with non-blocking/reversible electrodes (b) corresponding admittance plot and (c) corresponding Impedance plots.(d) The equivalent circuit of sample with blocking/irrreversible electrodes(e) corresponding admittance plot and (f) corresponding Impedance plots.

The samples are prepared with the varying the weight percentage of bismuth sulfide (1-10 wt.\%) to the maximum ion conducting polymer electrolyte (PEO: $\mathrm{NH}_{4} \mathrm{ClO}_{4}$ are in the wt.\% ratio 96:4). Complex impedance spectroscopy technique or a. c. method is used to measure the electrical conductivity of different polymeric films in the frequency range from $10 \mathrm{~Hz}$ to $100 \mathrm{KHz}$. Complex impedance spectroscopy was first applied by Bauerle [4] to measure the bulk conductivity of the solid electrolytes and it is now the most widely used technique. Complex impedance spectroscopy refers to the measurement of real and imaginary part of impedance/admittance at different frequencies. Impedance (Z)/admittance (Y) being a complex quantity can be written as:

$$
\begin{array}{lll}
\mathrm{Z}(\mathrm{w}) & = & \mathrm{Z}^{\prime}(\mathrm{w})-\mathrm{j} \mathrm{Z}^{\prime \prime}(\mathrm{w}) \\
\mathrm{Y}(\mathrm{w}) & = & \mathrm{G}(\mathrm{w})+\mathrm{j} \mathrm{B}(\mathrm{w})
\end{array}
$$

where $Z^{\prime}$ and $Z^{\prime \prime}$ are real and imaginary parts of the impedance respectively. $\mathrm{G}$ and $\mathrm{B}$ are the conductance and susceptance respectively. The plots of $Z^{\prime}(=Z \cos \theta)$ and $Z^{\prime \prime}(=Z \sin \theta)$ in the complex plane at various frequencies are known as impedance plots gives the frequency dispersion curves. These frequency dispersion curves provide information about the electrode-electrolyte interface, bulk resistance and grain boundary etc. Some typical complex admittance/impedance plots for simple circuits are shown in Figure 1. Depending upon the relaxation time of the circuit present in the system, one or more than one arcs are obtained. In the studies of admittance/impedance plots of ionic conductors, mainly two situations arises i.e. sample with non-blocking/reversible electrodes and sample with blocking/irreversible electrodes and are as follow:

\section{Sample with non-blocking/reversible electrodes}

In high frequency region, there is a geometrical capacitance $\left(C_{g}\right)$ in parallel with the bulk resistance $\left(R_{b}\right)$ for electrolytes having non-blocking/reversible electrodes. The equivalent circuit is shown in figure 1 (a) and its corresponding admittance and impedance plots are shown in figures 1 (b) and 1 (c). There will be no frequency dispersion at low frequencies in impedance plots. The intercept of dispersion curve on real axis will give the value of bulk resistance/conductance.

\section{Sample with blocking/irreversible electrodes}

An additional double layer capacitance $\left(\mathrm{C}_{\mathrm{dl}}\right)$ is in series with the $\mathrm{C}_{\mathrm{g}}-\mathrm{R}_{\mathrm{b}}$ combination for samples having blocking electrodes as shown in Figure. 1(d). So due to this there will be an additional low frequency dispersion region in admittance/impedance plots as shown in Figures 1(e) and 1(f). Polarization at electrode-electrolyte interface dominates over $\mathrm{C}_{\mathrm{g}}$ at low frequencies. As in an ideal case, electrodeelectrolyte interface are considered as perfectly smooth and 
flat, but it is not true in practical cases. In practical case, these impedance plots get modified and the intercept of the low frequency and high frequency dispersion curves on real axis (high frequency) gives a bulk resistance/conductance of the samples. In the present studies, we have used LCR Hioki 3522 meter working in the frequency range of $40 \mathrm{~Hz}$ to 100 $\mathrm{KHz}$ for the measurements of electrical conductivity. Impedance/admittance plots are drawn and the conductivity was calculated by using this relation

$$
\begin{aligned}
& \sigma=\mathrm{L} / \mathrm{R} . \mathrm{A} \\
& \sigma=\mathrm{GL} / \mathrm{A}
\end{aligned}
$$

where $G$ is the conductance which is determined from the admittance plots and $\mathrm{R}$ is the resistance which is determined from impedance plots, $\mathrm{L}$ is the distance between the electrodes and $\mathrm{A}$ is the area of cross-section of each electrode.
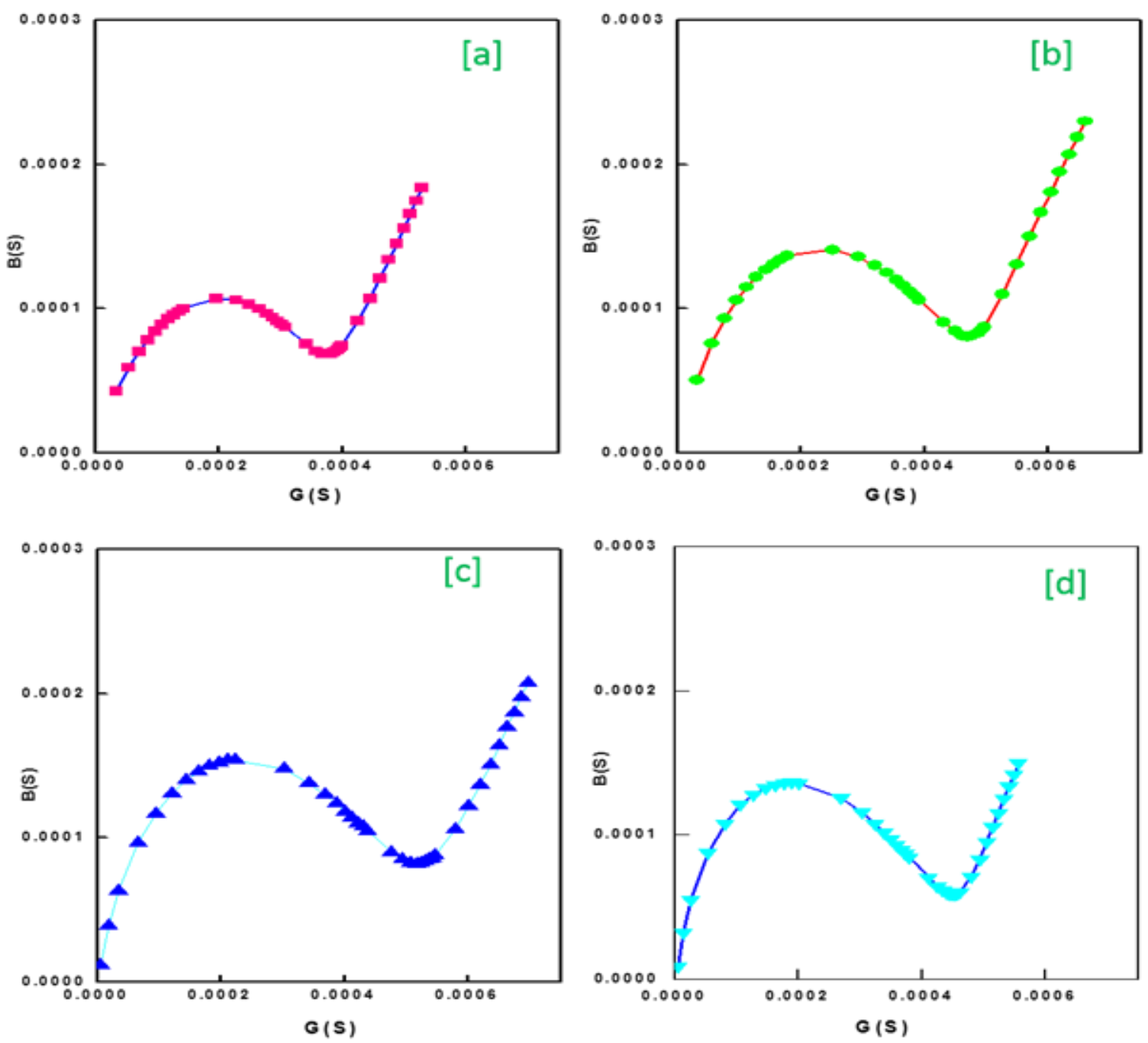

Figure 2: Complex impedance plots of polymer electrolyte PEO: $\mathrm{NH}_{4} \mathrm{ClO}_{4}$ with the dispersoid bismuth sulfide in different concentration (a) 4 wt.\% (b) 6 wt.\% (c) 8 wt.\% (d) 10 wt.\%

\section{RESULTS AND DISCUSSION}

The complex impedance plots of the different composites films are shown in the figure 2 . The plots are broadened semicircles due to the electrode electrolyte interface as stated in the section 2. The intercept on the horizontal axis (real axis) gives the value of the bulk conductance. The value of the bulk or the total conductivity is calculated by equation 1 .

Table 1. Conductivity measurement of the different composites films 


\begin{tabular}{|l|c|c|}
\hline \multicolumn{1}{|c|}{ Sample } & $\begin{array}{c}\text { Dopant } \mathrm{Bi}_{2} \mathrm{~S}_{3} \\
\text { concentration } \\
(\text { Wt. } \%)\end{array}$ & $\begin{array}{c}\text { Total } \\
\text { conductivity } \\
\left(\sigma_{\mathrm{T}}\right) \text { at } 303 \mathrm{~K} \\
\left(\mathrm{X} 10^{-6} \mathrm{~S} / \mathrm{cm}\right)\end{array}$ \\
\hline PEO: $\mathrm{NH}_{4} \mathrm{ClO}_{4}(96: 4)$ & 0 & 1.00 \\
\hline PEO: $\mathrm{NH}_{4} \mathrm{ClO}_{4}(96: 4)$ & 2 & 1.66 \\
\hline PEO: $\mathrm{NH}_{4} \mathrm{ClO}_{4}(96: 4)$ & 4 & 7.10 \\
\hline PEO: $\mathrm{NH}_{4} \mathrm{ClO}_{4}(96: 4)$ & 6 & 10.5 \\
\hline PEO: $\mathrm{NH}_{4} \mathrm{ClO}_{4}(96: 4)$ & 8 & 9.30 \\
\hline PEO: $\mathrm{NH}_{4} \mathrm{ClO}_{4}(96: 4)$ & 10 & 9.18 \\
\hline
\end{tabular}

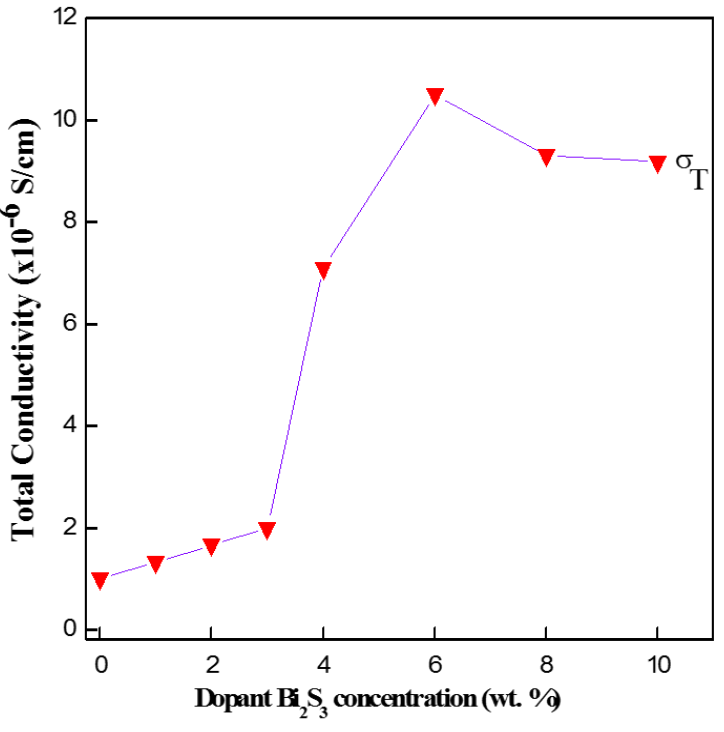

Figure 3: Variation of total conductivity with the weight percentage of dispersoid bismuth sulfide.

Table 1 and Figure 3 gives the variation of total conductivity with the different weight percentage of dispersoid bismuth sulfide. The dispersal of the dopant bismuth sulfide has enhanced overall conductivity of composites in the following way. The initial conductivity is the conductivity of the pristine polymer electrolyte with no dispersal of bismuth sulfide and conductivity is primarily due to ions which are in the partially dissociated states. Bismuth sulfide is the low conductivity dispersoid and it can be treated as insulator which decreases the ion association resulting generation of access ion carriers in the polymer electrolyte [19]. In addition to above, bismuth sulfide being the semiconducting nature also introduces the electronic/hole conductivity. The total conductivity first increases, attains the maxima at $6 \mathrm{wt}$ \% and then decreases. Such a variation of peaking at low threshold wt. $\%$ of the dispersoid can be explained by bunde et al percolation model [20].

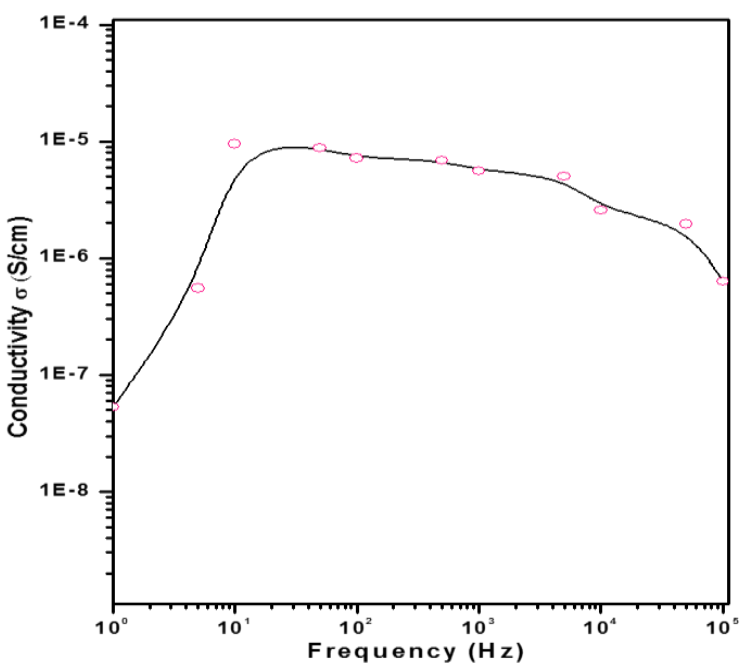

Figure 4: Total conductivity vs frequency plot for the polymer electrolyte PEO: $\mathrm{NH}_{4} \mathrm{ClO}_{4}$ with the 4 wt. \% dispersoid bismuth sulfide

Figure 4 shows logarithmic plot between conductivity and frequency. From the plot, it is clear that there is almost a plateau region from $50 \mathrm{~Hz}$ to $10 \mathrm{KHz}$ and there is decrease in the conductivity from this plateau region as the frequency decreases. This gives the low frequency dispersion. The small value of the conductivity in this this region is due to polarization of the charge carrier (ions) as a result of accumulation of the charge carriers at the electrodes electrolyte interface. During the ac measurements, the sample is considered as a microscopic dipole which follow with some delay space charge polarization as the applied electric field changes the direction. The conductivity in this dispersion depends on the easiness the dipole may translate the ions through the sample or with minimum delay. From the careful look from the plot, it can be seen that the conductivity decreases again at very high frequency due to increase of the delay discussed above at the very high frequency.

In polymer electrolyte composites films, the conductivity is due to two types of charge carries. The principal charge carries are ions but with the introduction of the bismuth sulfide dispersoid, it introduces the partial electronic/hole conductivity in the polymer electrolyte]. According to Wagner [21], the relation between the current and applied voltage are

$$
\begin{aligned}
& I_{e}=R T \frac{A}{L F} \cdot \sigma_{e}\left[1-\exp ^{\left(-\frac{V F}{R T}\right)}\right] \\
& I_{h}=R T \frac{A}{L F} \cdot \sigma_{h}\left[\exp ^{\left(\frac{V F}{R T}\right)}-1\right]
\end{aligned}
$$


Where $\mathrm{T}$ is the temperature in $\left({ }^{\mathrm{o}} \mathrm{K}\right), \mathrm{A}$ area of the sample, $\mathrm{L}$ is the thickness of the sample, $\mathrm{F}$ is the Faraday constant and $\mathrm{R}$ is a gas constant. At room temperature $(298 \mathrm{~K})$ and at moderate voltages, the value of $\exp (\mathrm{VF} / \mathrm{RT})>>1$, then two equations becomes

$$
\begin{gathered}
I_{e}=R T \frac{A}{L F} \cdot \sigma_{e} \\
I_{h}=R T \frac{A}{L F} \cdot \sigma_{h}\left[\exp { }^{\left(\frac{V F}{R T}\right)}\right]
\end{gathered}
$$

Hence from the above relation it is clear that the electronic conductivity or $I_{e}$ is independent at moderate high voltage and however $I_{h}$ it increases exponentially with applied voltage in the case of hole conductivity.

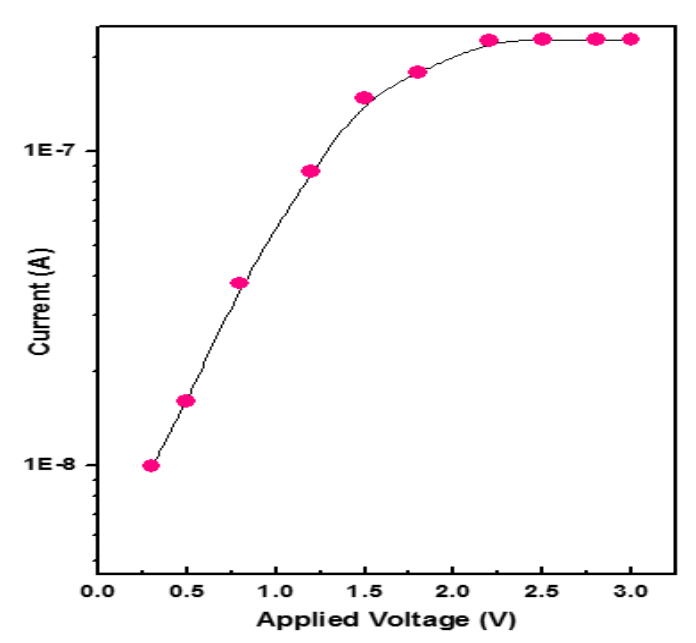

Figure 5: I-V Plot for the polymer electrolyte with the $6 \mathrm{wt} . \%$ bismuth sulfide dispersoid

Figure 5 shows the variation of the residual current with polarizing applied voltage for the 6 (wt. \%) of bismuth sulfide. From the plot, it is clear that the current initially increases at low voltage and then becomes constant at moderate voltages. Hence it is concluded that sample has electrons as the majority charge carriers and hence dispersoid bismuth sulfide is n type in the present composite system.

\section{CONCLUSION AND FUTURE SCOPE}

In summary, the polymer crystal composites films based on PEO: $\mathrm{NH}_{4} \mathrm{ClO}_{4}$ and dispersed with bismuth sulfide are prepared by in-situ method. Composites films are prepared by varying weight percentage of bismuth sulfide (0-10 wt. $\%$ ) and electrically characterized. Overall conductivity of the composite films is calculated from the complex impedance plots. Dispersal of bismuth sulfide has enhanced the total conductivity which peaks at 6 wt. $\%$ of dispersoid. The conductivity dispersion plot showed the plateau region for 50 $\mathrm{Hz}$ to $10 \mathrm{KHz}$ and polarization nature of ions at electrode electrolyte interface. Wagner's polarization or I-V studies show n-type behavior of dispersoid in the composite. The composite films will be characterized with detailed optical studies (SEM and TEM) for future research work.

\section{REFERENCES}

[1] P.V. Wright, "Electrical conductivity in ionic complexes of poly(ethylene oxide)," British Polymer Journal. vol 7: pp.319327,1975 .

[2] D.E. Fenton, J.M. Parker, P.V. Wright, "Complexes of alkali metal ions with poly(ethylene oxide)", Polymer. 14 pp. 589-589, 1973.

[3] J.R. MacCallum, C.A. Vincent, "Polymer Electrolyte Reviews", 1, 2, Elsevier, New York 1989, 1991.

[4] S. Chandra. "Superionic solids: Principles and Applications", North Holland, Amsterdam. 1981.

[5] A.F. Nogueira, J.R. Durrant, M.A. De Paoli. "Dye-Sensitized Nanocrystalline Solar Cells Employing a Polymer Electrolyte", Advanced Materials, Vol.13 pp.826-830, 2001.

[6] A. Chandra, S. Chandra, "Experimental observation of large-size fractals in ion-conducting polymer electrolyte films", Physical Review B. Vol.49, pp.633-636, 1994.

[7] S. A. Hashmi, A. Kumar and K. K. Maurya et.al, "Protonconducting polymer electrolyte I, The polyethylene oxide $+\mathrm{NH}_{4} \mathrm{ClO}_{4}$ system", Journal Physics. D, Vol.23 pp.13071314, 1990.

[8] W. Wang, P. Alexandridis, "Composite Polymer Electrolytes: Nanoparticles Affect Structure and Properties", Polymers, Vol.8, pp.387, 2016.

[9] A. Arya, A.L. Sharma, "Conductivity and Stability Properties of Solid Polymer Electrolyte Based on PEO-PAN $+\mathrm{LiPF}_{6}$ for Energy Storage", Applied Science Letter, Vol.2, pp.72-75, 2016.

[10] R.J. Sengwa, S. Choudhary, P. Dhatarwal, "Influences of ultrasonic- and microwave-irradiated preparation methods on the structural and dielectric properties of (PEO-PMMA) $\mathrm{LiCF}_{3} \mathrm{SO}_{3}-x$ wt $\%$ MMT nocomposite electrolytes" Ionics, Vol.2, pp. 95-109, 2015.

[11] A. Arya, A.L. Sharma and S. Sharma et.al. "Role of low salt concentration on electrical conductivity in blend polymeric films", Journal integrated Science \& Technology, Vol.4, pp.1720, 2016.

[12] M. Kumar and S.S. Sekhon, "Role of plasticizer's dielectric constant on conductivity modification of $\mathrm{PEO}-\mathrm{NH}_{4} \mathrm{~F}$ polymer electrolytes. European Polym J. Vol.38, pp.1297-1304, 2002.

[13] A. Arya, A.L. Sharma. "Polymer electrolytes for lithium ion batteries", a critical study, Ionics, Vol.23: Issue 3, pp.497-540, 2017.

[14] A. Chandra P.K. Singh, S. Chandra. "Semiconductor-dispersed polymer electrolyte composites", Solid State Ionics, Vol.154, pp.15-20, 2002.

[15] P.K. Singh, S. Chandra and A. Chandra, "Polymer electrolyte composites with dispersed semiconductors", Journal of Material Science Letter, Vol.21, pp.1393-1395, 2002.

[16] M. Kumar, A. Chandra, "In situ production of CuS particles in polymer electrolyte matrix for mixed ion+electron conduction", Ionics", Vol.16, pp.849-853 2010.

[17] M. Kumar, "Synthesis, electrical and thermal properties of PEO: $\mathrm{NH}_{4} \mathrm{ClO}_{4}$-camphor sulfonic acid-doped polyaniline composite", Materials Express. Vol.7: pp.223-229, 2017.

[18] M. Kumar, J.P. Sharma, "Electrical and Optical Studies of PVA Based Polymer Gel", Electrolytes" Material focus Vol.5, pp.1-6, 2016 
[19] J. Maier, "Enhancement of the Ionic Conductivity in Solid-SolidDispersions by Surface Induced Defects", Ber Bunsenges Phys Chem, Vol.88, pp.1057-1062, 1984.

[20] A. Bunde, W. Dietrich, E. Roman, Dispersed ionic conductors and percolation theory. Physical Review Letter. Vol.55, pp.5-8, 1985.

[21] C. Wagner. proc. $7^{\text {th }}$ meeting C.I.T.C.E., Lindau, Butterwords, Londan, pp. 361, 1957.

\section{AUTHORS PROFILE}

Dr. Manoj kumar pursued B.Sc. (NM) from Govt College Hamirpur (H.P.) in 1998. He did his M.Sc. (Physics) from Himachal Pradesh University Shimla in 2000. He obtained his Ph.D degree from Panjab University Chandigarh in 2009. $\mathrm{He}$ is currently working as Assistant Professor in Department of Physics, D.A.V. College

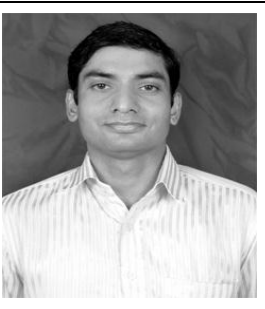
Abohar $(\mathrm{Pb})$ since 2006. He has published more than 10 research papers in reputed international journals including Thomson Reuters (SCI \& Web of Science) and 4 books in the international/national publishers. He has presented number of research papers in the national and international conferences. $\mathrm{He}$ is a member of P.G. Board of studies P.U. Chandigarh for the two terms. His topics of interest are characterization of polymer crystal composites, polymer-polymer composites, mixed ion and electron conductors, thin films and nanotechnology. He has 12 years of teaching experience and 17 years of research experience. 